\title{
Kinematic and electromyographic analysis of school children gait with and without load in the backpack
}

\author{
Jéssica Garcia Jorge ${ }^{1 *}$, Amanda Nascimento de Faria ${ }^{1}$, Daniel Antônio Furtado ${ }^{2}$, \\ Adriano Alves Pereira ${ }^{2}$, Eliane Maria de Carvalho ${ }^{1}$, Valdeci Carlos Dionísio ${ }^{1}$ \\ ${ }^{I}$ Neuromechanics and Physiotherapy Lab, Faculty of Physical Education and Physiotherapy, Federal University of Uberlândia, \\ Uberlândia, MG, Brazil. \\ ${ }^{2}$ Biomedical Engineering Lab, Faculty of Electrical Engineering, Federal University of Uberlândia, Uberlândia, MG, Brazil.
}

\begin{abstract}
Introduction: Excessive load on the backpacks can lead to musculoskeletal injuries and gait alterations. The objective of this study was to analyze the electromyographic (EMG) activity in association to the kinematic during the stance and balance phases of gait performed with and without the use of the backpack. Methods: Twelve volunteers have executed a gait cycle in 3 tasks: without the school backpack (SM), with a backpack with load equivalent to $10 \%$ (M10) and 20\% (M20) of the body weight (BW). It was evaluated the ankle, knee and hip angular excursion (AE), linear displacement (LD) of the toe and ankle, knee, hip, shoulder, head and EMG activity of the tibialis anterior (TA), vastus medialis (VM), rectus abdominis (RA), gastrocnemius lateral (GL), biceps femoris (BF) and spinal erector (EE) muscles. Results: In the LD in the stance phase there was an AP increase for the toe and ankle, hip and head $(\mathrm{p}<0.043)$. In the balance phase for VT (vertical) direction, the shoulder presented a smaller displacement as well as the toe, ankle, knee, hip, shoulder and head in the ML direction. In the AP direction, the toe displacement was smaller as well as the ankle $(\mathrm{p}<0.038)$. The AE in both phases was smaller for the hip $(p<0.006)$. In the balance phase the IEMG was higher for the RA $(p=0.034)$. Conclusion: These results suggest that the transport of school backpacks with loads of more than $10 \% \mathrm{BW}$ causes changes in the kinematic and in the muscular recruitment pattern.
\end{abstract}

Keywords Kinematic, Gait, Electromyography, Overload, School children.

\section{Introduction}

The majority of children in school age have been carrying backpacks with loads exceeding the limits recommended by the world Health Organization $(10 \%$ of the body weight - BW) (Rodríguez-Oviedo et al., 2012; Sheir-Neiss et al., 2003). The transport of excessive load induces biomechanical changes on the musculoskeletal system, and then it modifies the posture and the human gait (Ries et al., 2012; Rodríguez-Oviedo et al., 2012). Ries et al. (2012) observed head in previous position to the shoulders with the increased load of the school

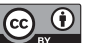

This is an Open Access article distributed under the terms of the Creative Commons Attribution License, which permits unrestricted use, distribution, and reproduction in any medium, provided the original work is properly cited.

How to cite this article: Jorge JG, Faria AN, Furtado DA, Pereira AA, Carvalho EM, Dionísio VC. Kinematic and electromyographic analysis of school children gait with and without load in the backpack. Res Biomed Eng. 2018; 34(1):9-18. DOI: 10.1590/2446-4740.04317.

*Corresponding author: Neuromechanics and Physiotherapy Lab, Faculty of Physical Education and Physiotherapy, Federal University of Uberlândia, Benjamin Constant street, 1286, CEP 38400-678, Uberlândia, MG, Brazil. E-mail: jehfisioterapi@gmail.com Received: 29 August 2017 / Accepted: 15 January 2018 backpack above $10 \%$ BW. Modifications like the increase of the anteroposterior balance and anterior trunk inclination, the increased cervical lordosis and lumbar and asymmetry of the shoulders were also identified as a result of the transport of excessive loads in the school backpack (Bauer and Freivalds, 2009; Lee and Shim, 2015; Ries et al., 2012; Rodríguez-Oviedo et al., 2012).

Kinematic modifications in the gait have been showed as result of the central nervous system attempt to adapt itself to the new condition of postural change. Among the main modifications; it could be observed the reduced speed, step length and vertical displacement, besides an increased lateral displacement (Hung et al., 2013) and the frequency of the step (Pascoe et al., 1997). It was also remarked that variable loads $(0 \%, 7.5 \%$, $10 \%, 12.5 \%$ and $15 \%$ of $\mathrm{BW}$ ) in adolescents reduce the speed and cadence, and also increase the time of double stance (Chow et al., 2011). The weight increased in their backpack can also produce previous tilt of the head and trunk during the gait (Grimmer et al., 1999). Therefore, the adequate displacement during the gait depends primarily on the amount of weight transported in a backpack (Rugelj and Sevsek, 2011). 
All these modifications could lead to change in the electromyographic (EMG) activity and muscular recruitment. The external force and mechanical tension produced by load in school backpack increases the demands on the musculature of all joints of the lower limb (Chow et al., 2011) and provoke some compensatory adjustments in posture required to maintain the dynamic balance during the gait (Malhotra and Gupta, 1965). For example, Al-Khabbaz et al. (2008) observed EMG alterations in trunk muscles (rectus abdominis and spinal erector) during the transport of schoolchildren backpacks.

The interpretation of EMG is important since it can provide information about motor control and facilitate the understanding of the kinetic and kinematic aspects of locomotion (Ozgül et al., 2012). The majority of studies aimed only at gait changes (Chow et al., 2011; Holt et al., 2005; Hong and Brueggemann, 2000; Hong and Cheung, 2003), but a few analyses were associated with the quantification of the EMG activity in the lower limbs (Hong and Cheung, 2003) and trunk (Al-Khabbaz et al., 2008; Chow et al., 2011). Moreover, when muscles were considered in this analysis, the assessment of muscular involvement was addressed only in a descriptive way through interviews made with the participants (Brackley et al., 2009; Rodríguez-Oviedo et al., 2012). The non-quantification of this analysis could miss important information on variability of EMG activity (Granata et al., 2005).

According to what was previously observed, we believe that checking the EMG activity in association to kinematic would help better understand the changes caused by the use of the backpack with excessive load on schoolchildren during the gait; in parallel, it contributes positively with the diagnosis and early therapeutic interventions (Ries et al., 2012). The objective of this study was to analyze the EMG activity of major muscles of the lower limb including: tibialis anterior (TA), vastus medialis (VM), gastrocnemius lateral (GL), biceps femoris (BF) and major muscles of the trunk as rectus abdominis (RA) and spinal erector (EE) in association with the kinematic (angular excursion and linear displacement) data during a gait performed with and without the use of school backpack. The hypothesis of this study was that the transport of school backpacks with loads over $10 \%$ of BW would result in changes in the kinematic and in the EMG activity. This is particularly important, once the children are both in the period of physical and motor development (Bauer and Freivalds, 2009; Hong et al., 2008) and changes that are not identified in the childhood tend to persist and/or worsen in the adult life, becoming into chronic lumbar pain, muscle fatigue and spine deviations (Hong and Cheung, 2003; Ries et al., 2012; Rodríguez-Oviedo et al., 2012).

\section{Methods}

\section{Subjects}

Twelve male children participated of the study, they were between 9 and 11 years old and had neither been inflicted with a musculoskeletal nor neurological injury, fractures or use of prosthesis in the lower limbs, whose parents and/or guardians signed the Free and Informed Consent Term (FICT). The averages age, height and weight of the participants were respectively $9.0 \pm 0.67$ years old, $136.51 \pm 4.6 \mathrm{~cm}$ and $33.7 \pm 6.9 \mathrm{~kg}$. This research has been approved by the Ethics Committee of the Federal University of Uberlândia (Protocol 857/11).

According to the World Health Organization (WHO), the male puberty starts at the age of 13 years old, while female puberty begins at around 9-10 years of age, and the puberty may be accompanied with various hormonal changes that cause musculoskeletal disorders as accelerated growth, extending the hips, appearance of breasts and changes in weight (Tanner et al., 1975). Considering the influence of these factors in gait and muscle activity (Aleixo et al., 2012; Sperotto et al., 2015), the authors decided to evaluate only male children before puberty.

\section{Instrumentation}

\section{Electromyography}

For the collection of EMG signal, the local of fixation for each electrode was cleaned with cotton soaked in $70 \%$ alcohol for 10 seconds, and, when necessary it was performed the hair waxing. The bipolar surface electrodes (DhT EASD1: $20 \mathrm{gr} ; 2 \mathrm{~cm} \times 0.6 \mathrm{~cm} \times 2.5 \mathrm{~cm}$; two parallel silver plates separated by $1 \mathrm{~cm}$; Gain $=20 x$; Input impedance $=10 \mathrm{G} \Omega ;$ Common mode rejection ratio $=90 \mathrm{~dB}$ ) were connected to the electromyographic equipment (MyosystemBr1 P84: DataHominis Technology Ltda, Brazil; Gain $=100 x$ (total gain $=2000 x)$; Band-pass filter $=15 \mathrm{~Hz}$ to $1000 \mathrm{~Hz}$; Sampling frequency $=2000 \mathrm{~Hz}$; Data recorded in microvolts $(\mu \mathrm{V}))$, which, in turn, was connected to a IBM-PC standard computer. The electrodes were positioned with a distance of $2 \mathrm{~cm}$ from each other and fixed with adhesive tape - adhesive plaster- on the tibialis anterior (TA), vastus medialis (VM), rectus abdominis (RA), gastrocnemius lateral (GL), biceps femoris $(\mathrm{BF})$ and spinal erector (EE), according to the orientation of the 'Surface Electromyography for the Non-Invasive Assessment of Muscles - BIOMED II' (SENIAM) (Hermens et al., 2000) (Figure 1). For all volunteers and data acquisitions, the sites were identified and prepared by the same researcher.

\section{Kinematics}

The kinematic data were obtained by a computerized system, with eight infrared cameras (OptiTrack FLEX V100R2, Natural Point, Corvallis, Oregon) arranged 

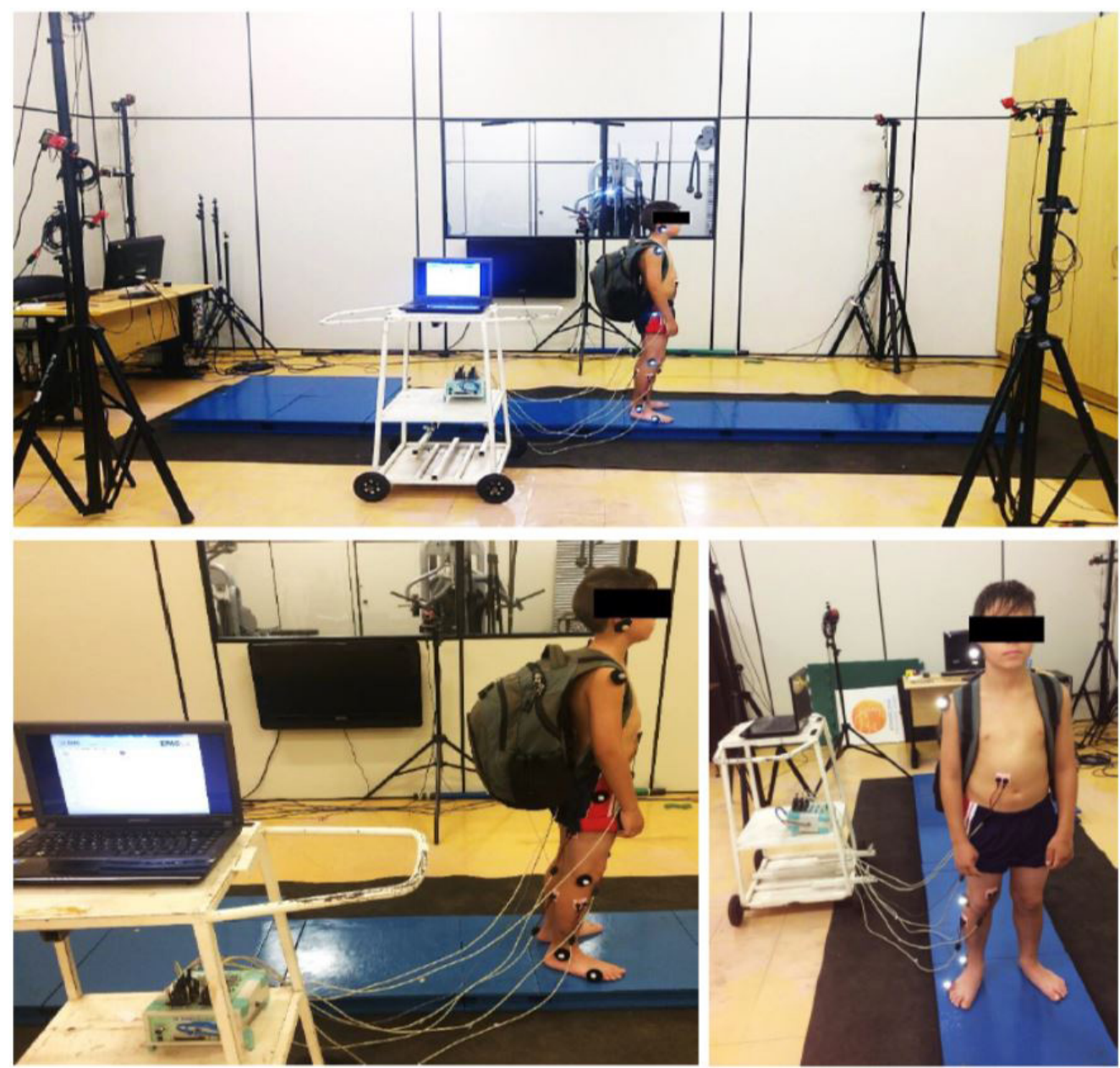

Figure 1. Experimental protocol, showing electrodes and kinematic markers in place.

so that they could capture the trajectory in $3 \mathrm{D}$ and register the linear displacement of gait by means of identification of circular reflexive markers fixed on the skin to a frequency of $100 \mathrm{~Hz}$. The reflexive markers could capture and reflect the infrared light, which is then captured by the camera lens. The local of fixation of each reflective marker was cleaned by a cotton cloth soaked in $70 \%$ alcohol for 10 seconds. When necessary, it was also performed the hair waxing. The markers were fixed on the following anatomic points: ear pinna (ear lobe - head); the lateral aspect of the acromion (shoulder); the greater trochanter of the femur (hip); lateral epicondyle (knee); lateral malleolus (ankle) and; the fifth metatarsal head (toe) (Figure 1).

\section{Procedures}

It was initially performed the evaluation of the personal data (name, age) and anthropometric data (weight and height collected by mechanical anthropometric scale) of the participants.
Then the cameras were calibrated and synchronized so that they could begin capturing images simultaneously. The system of cameras and the electromyograph was synchronized to start the images capture and the muscular activities at the same time, from the same manual shot (trigger) performed by the same researcher. A single school backpack was used for all the samples. She had bilateral shoulder handles, upholstered and adjustable, as well as a waist belt also adjustable. The backpack was weighed and then calculated the load according to the percentage of $\mathrm{BW}$ of each participant.

The data collection was carried out with the participants who were wearing only swimming shorts and they were barefoot. The EMG and kinematic data were captured during a gait step. The step was on a flat ground during three different tasks: without the backpack (SM); with a backpack loaded with $10 \% \mathrm{BW}$ of the participant (M10) and with a backpack loaded with $20 \%$ BW (M20). Before the data capture, the participants had 
gotten familiar with the procedure in order to obtain the gait performed as natural as possible. Each task lasted 4 seconds and they were repeated three times with a rest period of 30 seconds, being ordered randomly (using the software Excell 2003). At the end of each task, the participant was repositioned in demarcated position on the ground for the beginning of the new task.

\section{Data processing}

Data was processed offline by Excel (Microsoft, Office XP 2003) and KaleidaGraph (Synergy software, version 3.08). From the kinematic coordinates in 3D of the gait trajectory, the linear displacement (LD) it was calculated in anteroposterior (AP), vertical (VT) and mediolateral (ML) directions. A low-pass filter with cut-off frequency of $5 \mathrm{~Hz}$ filtered the kinematic data and subsequently the hip, knee and ankle angle displacement were calculated. The EMG signals were rectified (full wave), aligned, filtered at $25 \mathrm{~Hz}$, and normalized by peak of EMG activity. All procedures using the KaleidaGraph (Synergy software, version 3.08), and all kinematic data were normalized at the time by the gait cycle from $0 \%$ (first heel stride) to $100 \%$ (second heel stride) of the same foot (Figure 1). The average of three repetitions was calculated; from this average, it could be calculated the maximal LD, angular excursion - AE (maximal minus minimal angular displacement) of each task and the integral of the EMG activity (IEMG) during the stance and balance gait phases. These phases were defined by visual inspection (Ghoussayni et al., 2004) taking into account the analysis of the linear displacement of the marks of the ankle and the tiptoe (Figure 2).

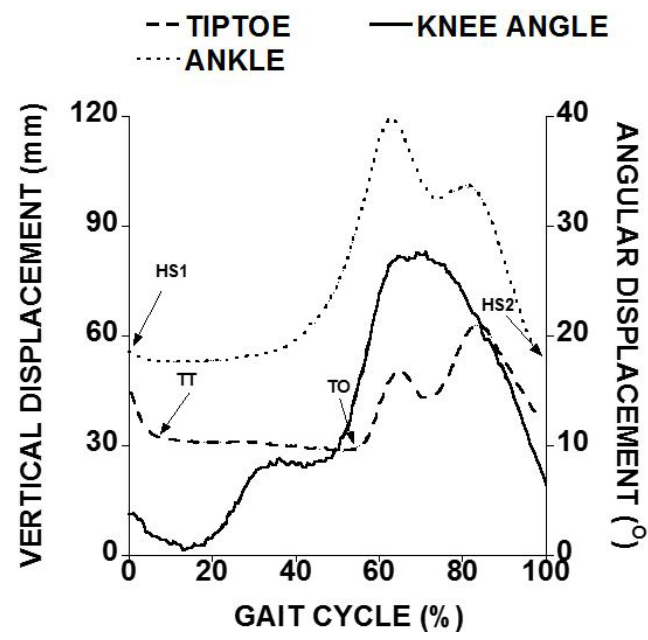

Figure 2. Vertical displacement and angular displacement of the gait cycle, from $0 \%$ (first heel stride) to $100 \%$ (second heel stride) for the same foot. HS1: first heel stride; HS2: second heel stride; TT: tiptoe touch; TO: removal of tiptoe.

\section{Statistical analysis}

The average of linear displacement, $\mathrm{AE}$ and the IEMG activity of all participants were organized in tables. The Shapiro-Wilk W test (Ghasemi and Zahediasl, 2012) did not confirme the normal distribution for all variables. So, they were applied the Wilcoxon test, in order to compare the tasks with and also without the load. The significance level was considered $\leq 0.05$.

Each participant was used for his own comparison, and therefore, we used a repeated measure test (General Linear Model) with Bonferroni adjustment. We used three level factors (conditions [M, M10, and M20] x [linear displacement, AE or IEMG]), for each phase (stance and balance) separately. When there was a significant condition effect, the post hoc comparison was used comparing two factors separately [M × M10], [M x M20] and [M10 x M20]. All the tests were performed in $\mathrm{IBM}^{\circ} \mathrm{SPSS}^{\circ}$ (version 22) and we used, for statistical, significance level at 0.05 for all comparisons.

\section{Results}

\section{Linear displacement}

The results showed that, in the stance phase, when the three conditions were compared for VT and ML direction, there was no significant difference (Table 1). However, for AP direction there were significant differences between the conditions. The post hoc showed that the AP direction was larger for toe and ankle in M20 condition compared with SM condition. Similar to that, M20 was larger for hip compared with M10 condition. Although, for head in AP direction, SM condition showed larger displacement compared with M10 and M20 conditions (Table 1).

In the balance phase the results reveled that in VT direction no differences were shown for toe, ankle, knee, hip and head; whereas shoulder presented difference. The shoulder displacement was smaller in M20 compared with M10 condition (Table 2). The AP and ML directions were different between conditions. The post hoc showed that M20 condition was smaller than M10 condition for toe, ankle, knee, hip, shoulder and head ML direction. In AP direction, during M20 condition, toe displacement was smaller compared to SM condition; in M20 condition and ankle displacement, it was also smaller compared to M10 condition (Table 2).

\section{Angular excursion - $A E$}

The AE during stance phase was similar for ankle and knee joints, although hip showed differences. In SM condition, the AE was smaller than M10 and M20 conditions (Figure 3; Table 1). The same results were observed during the balance phase, and hip AE was smaller in SM condition, compared with M10 and M20 conditions (Table 2). 
Table 1. Mean and standard deviation of kinematic variables for stance phase.

\begin{tabular}{|c|c|c|c|c|c|c|c|c|c|}
\hline \multirow{2}{*}{$\begin{array}{c}\text { Variables } \\
\text { Stance Phase } \\
\end{array}$} & \multicolumn{3}{|c|}{ Conditions } & \multicolumn{6}{|c|}{ Statistics } \\
\hline & $S M$ & M10 & M20 & SM vs & M10 & SM v & M20 & M10 & M20 \\
\hline \multicolumn{10}{|c|}{ Linear displacement ( $\mathrm{mm})$} \\
\hline & & & & $F$ & $P$ & $F$ & $p$ & $F$ & $p$ \\
\hline Toe ML & $-60.83(75.75)$ & $-57.05(80.89)$ & $-53.18(77.34)$ & NS & & & & & \\
\hline Toe AP & $-154.04(57.75)$ & $-172.00(52.69)$ & $-188.35(57.92)$ & 1.218 & 0.293 & 6.547 & 0.027 & 2.278 & 0.159 \\
\hline Toe VT & $32.85(3.33)$ & $31.93(3.19)$ & $32.11(3.50)$ & NS & & & & & \\
\hline Ankle ML & $-74.32(87.19)$ & $-68.85(89.99)$ & $-64.15(86.64)$ & NS & & & & & \\
\hline Ankle AP & $-250.04(54.94)$ & $-268.43(48.62)$ & $-284.54(52.67)$ & 1.283 & 0.282 & 6.882 & 0.024 & 2.219 & 0.164 \\
\hline Ankle VT & $57.17(7.25)$ & $57.23(7.53)$ & $56.28(7.16)$ & NS & & & & & \\
\hline Knee ML & $-60.75(71.47)$ & $-59.59(72.99)$ & $-53.97(66.69)$ & NS & & & & & \\
\hline Knee AP & $-209.89(64.10)$ & $-216.61(65.60)$ & $-236.77(67.33)$ & 0.161 & 0.696 & 2.994 & 0.112 & 3.455 & 0.090 \\
\hline Knee VT & $404.25(17.63)$ & 403.21 (18.09) & $402.35(18.15)$ & NS & & & & & \\
\hline Hip ML & $-31.42(49.73)$ & $-30.67(49.69)$ & $-23.35(41.98)$ & NS & & & & & \\
\hline Hip AP & $-226.57(59.86)$ & $-228.44(56.70)$ & $-250.88(51.49)$ & 0.013 & 0.912 & 2.719 & 0.127 & 5.224 & 0.043 \\
\hline Hip VT & $715.13(31.66)$ & $714.29(31.93)$ & $713.83(32.55)$ & NS & & & & & \\
\hline Shoulder ML & $-11.09(38.12)$ & $-10.23(33.45)$ & $-5.20(22.39)$ & NS & & & & & \\
\hline Shoulder AP & $-207.50(69.06)$ & $-179.45(56.48)$ & $-188.17(48.29)$ & 3.022 & 0.110 & 1.906 & 0.195 & 0.988 & 0.342 \\
\hline Shoulder VT & $1087.32(39.86)$ & $1080.34(39.24)$ & $1077.68(40.11)$ & NS & & & & & \\
\hline Head ML & $-91.22(84.85)$ & $-94.50(86.14)$ & $-92.00(78.40)$ & NS & & & & & \\
\hline Head AP & $-161.11(67.10)$ & $-114.36(49.18)$ & $-124.79(51.07)$ & 7.891 & 0.017 & 5.829 & 0.034 & 1.103 & 0.316 \\
\hline Head VT & $1216.51(44.02)$ & $1176.75(133.47)$ & $1202.86(43.95)$ & NS & & & & & \\
\hline \multicolumn{10}{|c|}{ Angular excursion (degree) } \\
\hline Ankle & $17.84(5.06)$ & $17.85(2.93)$ & $18.84(5.59)$ & NS & & & & & \\
\hline Knee & $6.70(2.97)$ & $6.48(2.98)$ & $6.50(2.27)$ & NS & & & & & \\
\hline Hip & $11.61(4.59)$ & $17.37(7.30)$ & $19.02(6.11)$ & 11.586 & 0.006 & 36.431 & 0.000 & 1.455 & 0.253 \\
\hline
\end{tabular}

The statistics include post hoc results comparing two factor separately using repeated measures SM vs M10, SM vs M20 and M10 vs M20 conditions, task without the school backpack (SM), with a backpack loaded equivalent to 10\% (M10) and 20\% (M20) of body weight (BW). When repeated measures, testing the main effect, were not significant $(\mathrm{p}>0.05$ ), post-hoc tests were not conducted (NS). Bold values indicate significant differences ( $<0.05$ ). ML: mediolateral; AP: anteroposterior; VT: vertical.

Table 2. Mean and standard deviation of kinematic variables for the balance phase.

\begin{tabular}{|c|c|c|c|c|c|c|c|c|c|}
\hline Variables & \multicolumn{3}{|c|}{ Conditions } & \multicolumn{6}{|c|}{ Statistics } \\
\hline Balance Phase & $S M$ & M10 & M20 & SM v & M10 & SM v & M20 & M10 v & M20 \\
\hline \multicolumn{10}{|c|}{ Linear displacement $(\mathrm{mm})$} \\
\hline & & & & $F$ & $P$ & $F$ & $p$ & $F$ & $p$ \\
\hline Toe ML & $-58.32(72.04)$ & $-60.02(75.21)$ & $-44.55(68.14)$ & 0.157 & 0.700 & 3.206 & 0.101 & 5.423 & 0.040 \\
\hline Toe AP & $222.99(78.73)$ & $200.20(76.12)$ & $170.88(60.80)$ & 1.582 & 0.235 & 5.975 & 0.033 & 2.917 & 0.116 \\
\hline Toe VT & $52.19(5.21)$ & $51.08(4.94)$ & $50.52(6.34)$ & NS & & & & & \\
\hline Ankle ML & $-73.01(83.40)$ & $-74.25(85.40)$ & $-58.71(78.99)$ & 0.081 & 0.782 & 3.217 & 0.100 & 5.853 & 0.034 \\
\hline Ankle AP & $141.29(76.28)$ & $118.44(70.57)$ & $90.98(56.92)$ & 1.594 & 0.233 & 5.571 & 0.038 & 2.560 & 0.138 \\
\hline Ankle VT & $96.52(8.05)$ & $96.27(8.75)$ & $96.13(9.26)$ & NS & & & & & \\
\hline Knee ML & $-65.92(73.83)$ & $-75.57(73.61)$ & $-56.90(69.32)$ & 1.948 & 0.190 & 1.503 & 0.246 & 7.871 & 0.017 \\
\hline Knee AP & $230.66(83.27)$ & $213.62(77.25)$ & $190.68(71.32)$ & 0.903 & 0.362 & 4.055 & 0.069 & 1.915 & 0.194 \\
\hline Knee VT & $413.09(18.66)$ & $412.49(18.60)$ & $410.92(18.22)$ & NS & & & & & \\
\hline Hip ML & $-57.66(61.00)$ & $-63.61(57.48)$ & $-44.91(55.70)$ & 1.054 & 0.327 & 2.601 & 0.135 & 10.798 & 0.007 \\
\hline Hip AP & $180.25(92.92)$ & $167.78(59.55)$ & $146.19(58.97)$ & 0.554 & 0.472 & 3.784 & 0.078 & 2.250 & 0.162 \\
\hline Hip VT & $717.27(33.44)$ & $718.81(31.23)$ & $717.66(32.04)$ & NS & & & & & \\
\hline Shoulder ML & $-52.27(51.87)$ & $-60.46(47.79)$ & $-39.80(47.49)$ & 2.179 & 0.168 & 1.552 & 0.239 & 10.012 & 0.009 \\
\hline Shoulder AP & $188.25(92.92)$ & $204.39(57.81)$ & $200.11(61.58)$ & 0.673 & 0.429 & 0.305 & 0.592 & 0.088 & 0.772 \\
\hline Shoulder VT & $1098.14(41.06)$ & $1091.63(39.45)$ & $1087.46(38.04)$ & 5.044 & 0.046 & 11.113 & 0.007 & 1.628 & 0.228 \\
\hline Head ML & $-139.82(106.39)$ & $-151.91(105.26)$ & $-131.46(105.07)$ & 3.058 & 0.108 & 0.848 & 0.377 & 8.428 & 0.014 \\
\hline Head AP & $235.34(86.15)$ & $260.52(68.39)$ & $263.63(69.85)$ & 1.351 & 0.270 & 1.678 & 0.222 & 0.045 & 0.835 \\
\hline Head VT & $1221.48(45.96)$ & $1184.52(135.02)$ & $1210.98(43.34)$ & NS & & & & & \\
\hline \multicolumn{10}{|c|}{ Angular excursion (degree) } \\
\hline Ankle & $19.78(5.16)$ & $19.15(2.57)$ & $21.54(3.79)$ & NS & & & & & \\
\hline Knee & $39.01(10.40)$ & $38.71(9.60)$ & $38.29(9.07)$ & NS & & & & & \\
\hline Hip & $15.11(5.49)$ & $19.07(5.42)$ & $20.69(6.32)$ & 12.244 & 0.005 & 17.644 & 0.001 & 2.862 & 0.119 \\
\hline
\end{tabular}

The statistics include post hoc results comparing two factors separately using repeated measures SM vs M10, SM vs M20 and M10 vs M20 conditions; task without the school backpack (SM), with a backpack with load equivalent to $10 \%$ (M10) and 20\% (M20) of body weight (BW). When repeated measures, testing the main effect, were not significant $(\mathrm{p}>0.05$ ), post-hoc tests were not conducted (NS). Bold values indicate significant differences $(\mathrm{p}<0.05$ ). ML: mediolateral; AP: anteroposterior; VT: vertical. 


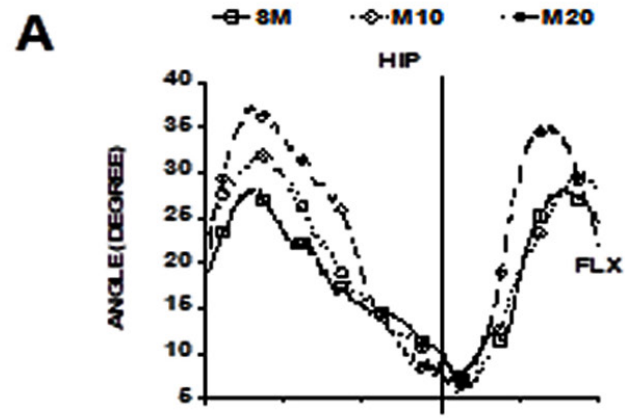

B
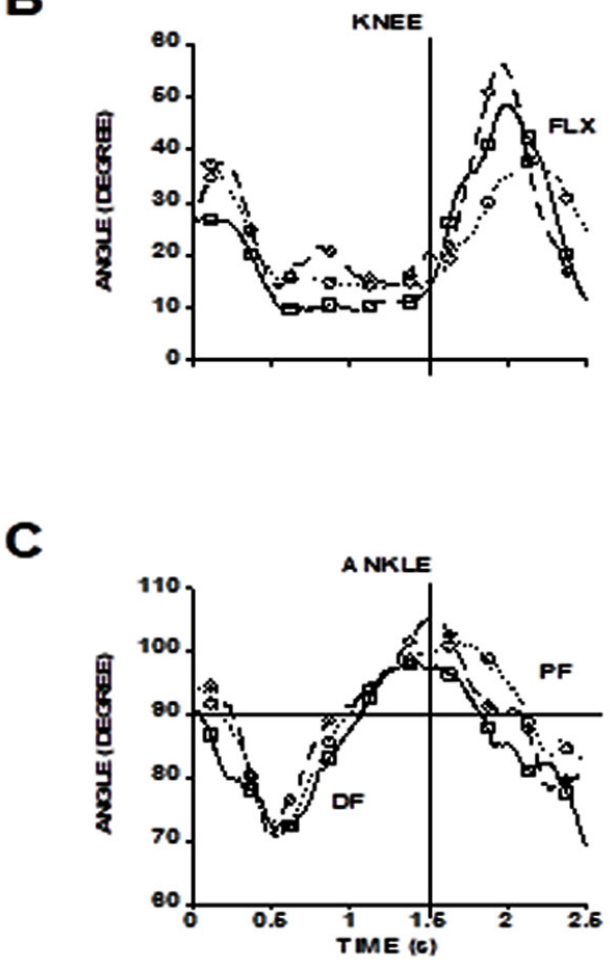

Figure 3. Time series of the hip average (A), knee (B) and ankle (C) angle displacement performed by one of volunteer executing a task without the school backpack (SM), carrying a backpack with the load equivalent to $10 \%$ (M10) and 20\% (M20) of body weight (BW). The vertical line in each plot represents the toe off event. FLX: flexion; DF: dorsiflexion; PF: plantar flexion.

\section{Electromyographic activity}

The integral of the electromyographic signal (IEMG) showed that there were no differences during stance and balance phases between the muscles studied, except for RA during the balance phase. The IEMG was larger in SM condition compared with M20 condition (Figure 4; Table 3).
Table 3. Integrated electromyographic signals (IEMG) in the gait balance phase in the different tasks.

\begin{tabular}{|c|c|c|}
\hline \multicolumn{3}{|c|}{ Median (Percentile 25-75) (Wilcoxon) } \\
\hline Variables & Balance phase & p value \\
\hline \multicolumn{3}{|c|}{ TA } \\
\hline SM & $13.65(11.07-15.65)$ & $0.209^{\&}$ \\
\hline M10 & $11.85(9.47-15.02)$ & $0.079 *$ \\
\hline M20 & $10.55(9.20-12.80)$ & $0.480^{\Omega}$ \\
\hline \multicolumn{3}{|c|}{ GL } \\
\hline SM & $13.12(11.87-17.05)$ & $0.875^{\&}$ \\
\hline M10 & $15.39(10.89-17.50)$ & $0.875^{*}$ \\
\hline M20 & $13.39(11.23-16.00)$ & $0.307^{\Omega}$ \\
\hline \multicolumn{3}{|c|}{ RA } \\
\hline SM & $33.00(22.31-41.02)$ & $0.099^{\&}$ \\
\hline M10 & $24.39(20.86-35.56)$ & $0.034 *$ \\
\hline M20 & $20.52(15.66-37.99)$ & $0.157^{\Omega}$ \\
\hline \multicolumn{3}{|c|}{$\mathbf{E E}$} \\
\hline SM & $18.76(13.29-22.89)$ & $0.937^{\&}$ \\
\hline M10 & $16.39(13.10-27.82)$ & $0.307 *$ \\
\hline M20 & $15.53(10.07-22.63)$ & $0.307^{\Omega}$ \\
\hline \multicolumn{3}{|c|}{$\mathbf{V M}$} \\
\hline SM & $18.37(13.75-23.82)$ & $0.637^{\&}$ \\
\hline M10 & $16.95(14.61-21.09)$ & $0.084 *$ \\
\hline M20 & $16.16(11.75-20.45)$ & $0.388^{\Omega}$ \\
\hline \multicolumn{3}{|c|}{ BF } \\
\hline SM & $24.52(18.29-27.41)$ & $0.875^{\&}$ \\
\hline M10 & $24.13(21.14-28.42)$ & $0.753 *$ \\
\hline M20 & $22.80(20.51-26.07)$ & $0.530^{\Omega}$ \\
\hline
\end{tabular}

$\&=\mathrm{SM}$ vs M10; $*=\mathrm{SM}$ vs M20 ${ }^{\Omega}=\mathrm{SM}$ vs M20. Task without the school backpack (SM), with a backpack loaded equivalent to 10\% (M10) and 20\% (M20) of body weight (BW); TA: Tibialis anterior; GL: Gastrocnemius lateral; RA: Rectus abdominis; EE: Spinal erector; VM: Vastus medialis; $\mathrm{BF}$ : Biceps femoris. $\mathrm{P}<0.05$ significant difference for the electromyographic activity between tasks.

\section{Discussion}

The objective of this study was to analyze the EMG activity in association with the kinematics during a gait performed with and without load in the backpack.

During the stance phase, the results showed larger LD for foot, ankle and hip, but reduced for head in AP direction with increased load. There were no differences in the VT and ML displacements on the comparison among the conditions. The increased load in the backpack produced a vector force in the inferior and posterior direction, which is maximum during double stance phase (Xu et al., 2009) pushing down the posterior and limiting the upper body movements.

Studies by Pau et al. $(2012 ; 2013 ; 2015 ; 2016)$ observed an increase in the plantar pressure peak after increasing the backpack weight, which expresses the influence of the load generating downward force against the ground. For these authors, the impact of backpack 
A

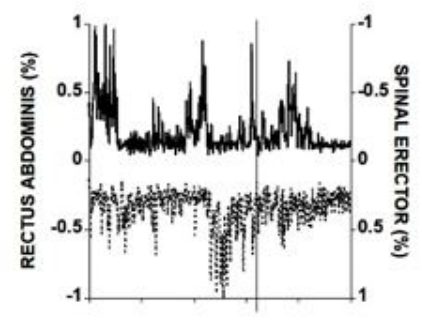

D

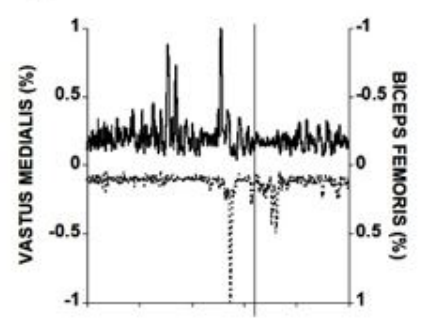

G

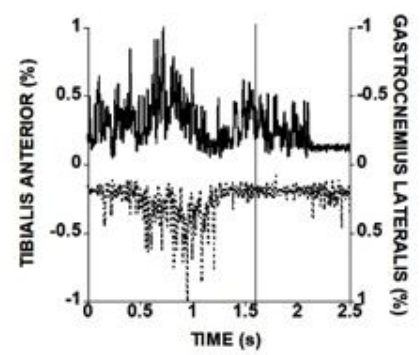

B

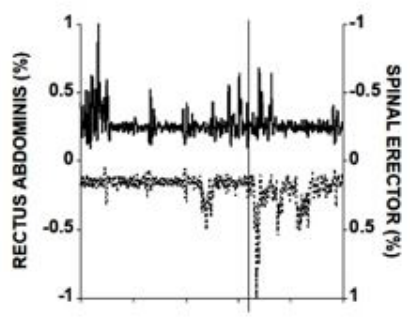

E

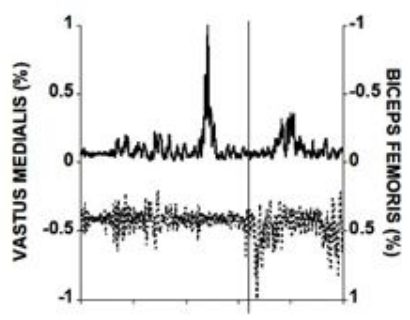

H

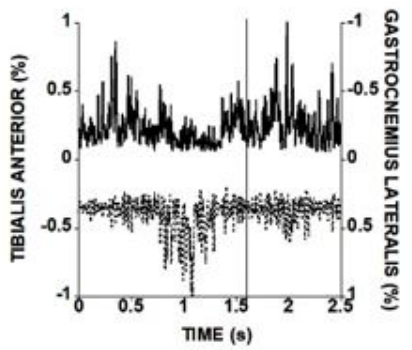

C

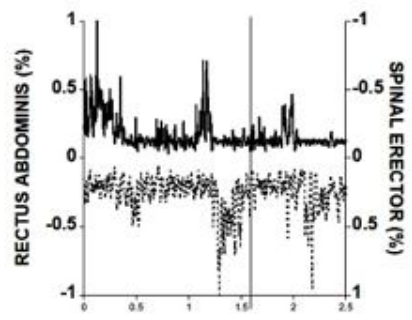

$\mathbf{F}$

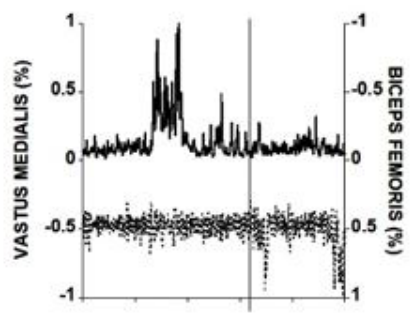

Figure 4. Time series of the averaged normalized EMG (percent of peak) for RA and EE (A-C), VM and BF (D-F) and TA and GL (G-I) performed by one of the volunteers. The vertical line in each plot represents the toe of the event. It is also shown the task without the school backpack (SM), with a backpack with the load equivalent to $10 \%$ (M10) and 20\% (M20) of body weight (BW).

transport is more evident in the foot/ground interaction than on short-term gait characteristics. The larger LD in the AP direction for foot, ankle and hip with load observed in this study could be related with the deceleration of movement and the forward movement to the next step. One of the main functions of the motor control is to guide the body in space, which involves the posture maintenance to minimize the disturbance of the balance and maintain stabilized the center of gravity. When the backpack with excessive load is transported, the center of mass is pulled to posterior direction. In the attempt to return to the appropriate position, similar to no load condition, the trunk moves to the opposite side tilting then forward, such adjustment helps the body minimize energy costs and increase the efficiency of the gait when carrying weight (Bloom and Woolhull-McNeal, 1987; Hong and Cheung, 2003).

Also, increasing AE of hip and smaller head LD during stance phase suggests a retraction of the shoulders as compensation to the previous inclination of the trunk during the movement. Although our results did not show 
differences in the shoulder similar to the study and Mosaad and Abdel-Aziem (2015), it is known that the backpack load weight generates larger forces of tension under the shoulder straps exerting increased pressure in the lower direction while its movement is limited (Hadid et al., 2012; Mackie et al., 2005). Thus, we can assume that the addition of load limits the displacement of the head as it has been suggested in several studies (Khallaf et al., 2016; Kistner et al., 2012) carried out without dislocation of the shoulder and analysis of the influence of load.

In the balance phase, the lowest VT shoulder LD expressed the limitation of movement imposed by the load (Hadid et al., 2012; Mackie et al., 2005; Xu et al., 2009). At this phase, there was a reduction in the ML displacement for all joints with larger load, which is justified by the need of the body to increase the entire abduction of the lower extremity in order to amplify the base of stance and then keep the balance to the next stance phase. This finding corroborates the study of Pau and Pau (2010) that also noted greater ML displacement caused by the weight of the backpack, suggesting that the load use could provoke a poor balance, increasing in children the risk for accidental falls.

On this phase yet, there was a reduction of AP displacement of the ankle and toe, as observed by Pascoe et al. (1997). According to England and Granata (2007), one shorter step favors the correction by the nervous system of the posture during the gait, being commonly adopted to compensate kinematic disorders or control errors. Besides the influence of load (Pascoe et al., 1997) and attempt to postural correction (England and Granata, 2007), all conditions were made barefoot, which produces short step length (Dames and Smith, 2015). In relation to the $\mathrm{AE}$, the results at this phase (balance) are similar to the previous phase, and this is justified again by larger retraction of the shoulders due to the addition of load in the backpack.

The RA muscle showed decreased EMG activity in the balance phase when it was compared to SM and M20 tasks, which can be explained by the compensatory postural mechanism retraction of the shoulder, as it has already been suggested in this study. Thus less RA muscle activity was required and possible increase in EMG activity for other muscles that were not evaluated in this study, like pectoralis major. Previous study (Habibi, 2012) strengthens the hypothesis of the measure identifying maximum upper trapezius muscle activation and minimum for muscle RA. Hong et al. (2008) also found similar results, demonstrating an increase in EMG activity and the presence of muscle fatigue in trapezius (upper and lower fiber), indicating greater weight directed toward the shoulder girdle region, while not EMG significant change to the RA muscle, even in gait long distance.
Kim et al. (2008) also suggest that the backpack load tends to overload the scapular waist and shoulders, with the stance made by muscles like the pectoralis major, not evaluated in this study. For Rugelj and Sevsek (2011), Hong et al. (2008) and Ramprasad et al. (2010), the weight directed to scapular waist associated with trunk inclination commonly manifest as a way of adapting to the new position, aiming to stabilize the trunk. The results of this study revealed the absence of significant EMG alteration to the EE muscle in both phases of the gait. These results are similar to those observed by Hong and Cheung. (2002). For Knapik et al. (1996), the increase of the EMG activity of EE muscles is only pronounced when the mass of the load exceeds $30-40 \mathrm{~kg}$, once higher loads generate greater trunk posterior trunk inclination.

For the other muscles of the lower limb, VM and BF, those findings are in accordance with the study of Simpson et al. (2012), who suggested that the muscle activation of the lower limbs is relatively unchanged, even during prolonged transport. For Al-Khabbaz et al. (2008), the lack of EMG change suggests that the external load has little effect on the muscles of the lower limbs. EMG activity is not a response to mechanical work itself, but it is highly dependent on other factors, such as the speed of the step, frequency and distance of the load transport (Bobet and Norman, 1982; 1984), which could explain the absence of muscle activity. So, our initial hypothesis was not supported.

Some limitations may be observed in this study. First, the sample could be considered smaller; however, some similar studies had compatible samples with ours (Granata et al., 2005; Hong et al., 2008). The gait analysis, in a single stride, was also performed in several studies being described as sufficient to present important results on kinematic and EMG alterations (Brackley et al., 2009; Holt et al., 2005; Hong and Brueggemann, 2000; Hong and Cheung, 2003; Hong et al., 2008). The absence of analysis and control about the gait speed could also be considered another limitation, but the objective of this study was to simulate a situation of trips normally used in the school routine. In these aspects, it is important to emphasize that those limitations were also observed in previous studies (Bauer and Freivalds, 2009; Granata et al., 2005; Hong and Cheung, 2002; Hong et al., 2008; Kim et al., 2008). Finally, the electromyographic analysis was also insufficient in this study, but enough to present significant results to the proposed question. It is suggested that new studies are performed with a richer electromyographic analysis during the gait.

The findings of this study suggest that the backpack transport with a load of $10 \%$ of body weight of schoolchildren causes significant kinematics changes during both phases of the gait, but EMG activity changes only for RA muscle during the balance phase. 


\section{Acknowledgements}

This work has been supported by the Brazilian agencies $\mathrm{CNPq}$ and FAPEMIG.

\section{References}

Aleixo AA, Guimarães EL, Walsh IAP, Pereira K. Influence of overweight and obesity on posture, overall praxis and balance in schoolchildren. J Hum Growth Dev. 2012; 22(2):239-45. http://dx.doi.org/10.7322/jhgd.44937.

Al-Khabbaz YS, Shimada T, Hasegawa M. The effect of backpack heaviness on trunk-lower extremity muscle activities and trunk posture. Gait Posture. 2008; 28(2):297-302. PMid:18329270. http://dx.doi.org/10.1016/j.gaitpost.2008.01.002.

Bauer DH, Freivalds A. Backpack load limit recommendation for middle school students based on physiological and psychophysical measurements. Work. 2009; 32(3):339-50. http://dx.doi.org/10.3233/WOR-2009-0832. PMid:19369726.

Bloom D, Woolhull-McNeal AP. Postural adjustments while standing with two types of loaded backpack. Ergonomics. 1987; 30(10):1425-30. http://dx.doi.org/10.1080/00140138708966036.

Bobet J, Norman RW. Effects of load placement on back muscle activity in load carriage. Eur J Appl Physiol. 1984; 53(1):715. PMid:6542504. http://dx.doi.org/10.1007/BF00964693.

Bobet J, Norman RW. Use of the average electromyogram in design evaluation investigation of a whole-body task. Ergonomics. 1982; 25(12):1155-63. PMid:7160362. http:// dx.doi.org/10.1080/00140138208925072.

Brackley HM, Stevenson JM, Selinger JC. Effect of backpack load placement on posture and spinal curvature in prepubescent children. Work. 2009; 32(2):351-60. http://dx.doi.org/10.3233/ WOR-2009-0833. PMid:19369727.

Chow DH, Hin CK, Ou D, Lai A. Carry-over effects of backpack carriage on trunk posture and repositioning ability. Ergonomics. 2011; 41(5):530-5. http://dx.doi.org/10.1016/j. ergon.2011.04.001.

Dames KD, Smith JD. Effects of load carriage and footwear on spatiotemporal parameters, kinematics, and metabolic cost of walking. Gait Posture. 2015; 42(2):122-6. PMid:25985924. http://dx.doi.org/10.1016/j.gaitpost.2015.04.017.

England SA, Granata KP. The influence of gait speed on local dynamic stability of walking. Gait Posture. 2007; 25(2):172-8. PMid:16621565. http://dx.doi.org/10.1016/j.gaitpost.2006.03.003.

Ghasemi A, Zahediasl S. Normality tests for statistical analysis: a guide for non-statisticians. Int J Endocrinol Metab Disord. 2012; 10(2):486-9. PMid:23843808. http://dx.doi.org/10.5812/ ijem.3505.

Ghoussayni S, Stevens C, Durham S, Ewins D. Assessment and validation of a simple automated method for the detection of gait events and intervals. Gait Posture. 2004; 20(3):266-72. PMid:15531173. http://dx.doi.org/10.1016/j.gaitpost.2003.10.001.

Granata KP, Padua AD, Abel FM. Repeatability of surface EMG during gait in children. Gait Posture. 2005; 22(4):346-50. PMid:16274917. http://dx.doi.org/10.1016/j.gaitpost.2004.11.014.
Grimmer KA, Williams MT, Gill TK. The associations between adolescent head-on-neck posture, backpack weight, and anthropometric features. Spine. 1999; 24(21):2262-7. PMid:10562994. http://dx.doi.org/10.1097/00007632199911010-00015.

Habibi A. Weight varying effects of carrying schoolbags on electromyographic changes of trunk muscles in twelve-year old male students. Int J Med. 2012; 2(4):314-8.

Hadid A, Belzer N, Shabshin N, Zeilig G, Gefen A, Epstein Y. The effect of mechanical strains in soft tissues of the shoulder during load carriage. J Biomech. 2012; 48(15):4160-5. PMid:26542788. http://dx.doi.org/10.1016/j.jbiomech.2015.10.020.

Hermens HJ, Freriks B, Disselhorst-Klug C, Rau G. Development of recommendation for SEMG sensor and sensor placement procedures. J Electromyogr Kinesiol. 2000; 10(5):361-74. PMid:11018445. http://dx.doi.org/10.1016/S1050-6411(00)00027-4

Holt KG, Wagenaar RC, Kubo M, LaFiandra ME, Obusek JP. Modulation of force transmission to the head while carrying a backpack load at different walking speeds. J Biomech. 2005; 38(8):1621-8. PMid:15958219. http://dx.doi.org/10.1016/j. jbiomech.2004.07.033.

Hong Y, Brueggemann G. Changes in gait patterns in 10-yearold boys with increasing loads when walking on a treadmill. Gait Posture. 2000; 11(3):254-9. PMid:10802438. http://dx.doi. org/10.1016/S0966-6362(00)00055-2.

Hong Y, Cheung C. Electromyographic responses of back Muscles during load carriage walking in children. In: Proceedings of the 20th International Symposium on Biomechanics in Sports; 2002; Cáceres, Spain. Spain: ISBS; 2002. p. 405-8.

Hong Y, Cheung C. Gait and posture responses to backpack load during level walking in children. Gait Posture. 2003; 17(1):28-33. PMid:12535723. http://dx.doi.org/10.1016/ S0966-6362(02)00050-4.

Hong Y, Li JX, Fong DT. Effect of prolonged walking with backpack loads on trunk muscle activity and fatigue in children. J Electromyogr Kinesiol. 2008; 18(6):990-6. PMid:17720538. http://dx.doi.org/10.1016/j.jelekin.2007.06.013.

Hung YC, Meredith GS, Gill SV. Influence of dual task constraints during walking for children. Gait Posture. 2013; 38(3):450-4. PMid:23384484. http://dx.doi.org/10.1016/j. gaitpost.2013.01.009.

Khallaf ME, Fayed EE, Ashammary RA. The effect of schoolbag weight on cervical posture in schoolchildren. Turk J Phys Med Rehab. 2016; 1(62):16-21. http://dx.doi.org/10.5606/ tftrd.2016.12754.

Kim MH, Yi CH, Kwon OY, Cho SH, Yoo WG. Changes in neck muscle electromyography and forward head posture of children when carrying schoolbags. Ergonomics. 2008; 51(6):890-901. PMid:18484402. http://dx.doi.org/10.1080/00140130701852747.

Kistner F, Fiebert I, Roach K. Effect of backpack load carriage on cervical posture in primary schoolchildren. Work. 2012; 41(1):99-108. http://dx.doi.org/10.3233/WOR-2012-1289. PMid:22246310.

Knapik J, Harman E, Reynolds K. Load carriage using packs: a review of physiological, biomechanical and medical aspects. 
Appl Ergon. 1996; 27(3):207-16. http://dx.doi.org/10.1016/00036870(96)00013-0. PMid:15677062.

Lee S, Shim J. The effects of backpack loads and spinal stabilization exercises on the dynamic foot pressure of elementary school children with idiopathic scoliosis. J Phys Ther Sci. 2015; 27(7):2257-60. PMid:26311964. http://dx.doi. org/10.1589/jpts.27.2257.

Mackie HW, Stevenson JM, Reid SA, Legg SJ. The effect of simulated school load carriage configurations on shoulder strap tension forces and shoulder interface pressure. Appl Ergon. 2005; 36(2):199-206. PMid:15694074. http://dx.doi. org/10.1016/j.apergo.2004.10.007.

Malhotra MS, Gupta JS. Carrying of school bags by children. Ergonomics. 1965; 8(1):55-60. http://dx.doi. org/10.1080/00140136508930774.

Mosaad DM, Abdel-Aziem AA. Backpack carriage effect on head posture and ground reaction forces in school children. Work. 2015; 52(1):203-9. PMid:26410235. http://dx.doi. org/10.3233/WOR-152043.

Ozgül B, Akalan NE, Kuchimov S, Uygur F, Temelli Y, Polat MG. Effects of unilateral backpack carriage on biomechanics of gait in adolescents: a kinematic analysis. Acta Orthop Traumatol Turc. 2012; 46(4):269-74. PMid:22951758. http:// dx.doi.org/10.3944/AOTT.2012.2678.

Pascoe DD, Pascoe DE, Wang YT, Shim DM, Kim CK. Influence of carrying book bags on gait cycle and posture of youths. Ergonomics. 1997; 40(6):631-41. PMid:9174414. http://dx.doi.org/10.1080/001401397187928.

Pau M, Kim S, Nussbaum MA. Does load carriage differentially alter postural sway in overweight vs. normal-weight schoolchildren? Gait Posture. 2012; 35(3):378-82. PMid:22088849. http:// dx.doi.org/10.1016/j.gaitpost.2011.10.354.

Pau M, Leban B, Corona F, Gioi S, Nussbaum MA. Schoolbased screening of plantar pressures during level walking with a backpack among overweight and obese schoolchildren. Ergonomics. 2016; 59(5):697-703. PMid:26226045. http:// dx.doi.org/10.1080/00140139.2015.1077275.

Pau M, Leban B, Pau M. Alterations in the plantar pressure patterns of overweight and obese schoolchildren due to backpack carriage. J Am Podiatr Med Assoc. 2013; 103(4):306-13. PMid:23878383. http://dx.doi.org/10.7547/1030306.

Pau M, Mandaresu S, Leban B, Nussbaum MA. Short-term effects of backpack carriage on plantar pressure and gait in schoolchildren. J Electromyogr Kinesiol. 2015; 25(2):406-12. PMid:25499084. http://dx.doi.org/10.1016/j.jelekin.2014.11.006.

Pau M, Pau M. Postural sway modifications induced by backpack carriage in primary school children: a case study in Italy. Ergonomics. 2010; 53(7):872-81. PMid:20582768. http://dx.doi.org/10.1080/00140139.2010.489965.

Ramprasad M, Alias J, Raghuveer KA. Effect of Backpack Weight on Postural Angles in Preadolescent Children. Indian Pediatr. 2010; 47(7):575-80. PMid:20019396. http://dx.doi. org/10.1007/s13312-010-0130-2.

Ries LG, Martinello M, Medeiros M, Cardoso M, Santos GM. The effects of different backpacks weights on postural alignment of children of school age. Motricidade. 2012; 8(4):87-95. http:// dx.doi.org/10.6063/motricidade.8(4).1556.

Rodríguez-Oviedo P, Ruano-Ravina A, Pérez-Ríos M, García FB, Gómez-Fernández D, Fernández-Alonso A, Carreira-Núñez I, García-Pacios P, Turiso J. School children's backpacks, back pain and back pathologies. Arch Dis Child. 2012; 97(8):730-2. PMid:22408188. http://dx.doi.org/10.1136/ archdischild-2011-301253.

Rugelj D, Sevsek F. The effect of load mass and its placement on postural sway. Appl Ergon. 2011; 42(6):860-6. PMid:21356532. http://dx.doi.org/10.1016/j.apergo.2011.02.002.

Sheir-Neiss GI, Kruse RW, Rahman T, Jacobson LP, Pelli JA. The association of backpack use back pain in adolescents. Spine. 2003; 28(9):922-30. PMid:12942009. http://dx.doi. org/10.1097/01.BRS.0000058725.18067.F7.

Simpson KM, Munro BJ, Steele J. Does load position affect gait and subjective responses of females during load carriage? Appl Ergon. 2012; 43(3):479-85. PMid:21831354. http://dx.doi. org/10.1016/j.apergo.2011.07.005.

Sperotto F, Brachi S, Vittadello F, Zulian F. Musculoskeletal pain in schoolchildren across puberty: a 3-year follow-up study. Pedi Rheumatol Journal. 2015; 13:16. http://dx.doi. org/10.1186/s12969-015-0014-z. PMid:25976338.

Tanner JM, Whitehouse RH, Marshall WA, Carter BS. Prediction of adult height from height, bone age, and occurrence of menarche, at ages 4 to 16 with allowance for midparent height. Arch Dis Child. 1975; 50(1):14-26. PMid:164838. http://dx.doi. org/10.1136/adc.50.1.14

Xu X, Hsiang SM, Mirka GA. The effects of a suspended-load backpack on gait. Gait Posture. 2009; 29(1):151-3. PMid:18693016. http://dx.doi.org/10.1016/j.gaitpost.2008.06.008. 